question that the problem of the chemistry of the life processes will be found to be based on them.

A knowledge of German provides, therefore, the student with the key to a door through which he can find much knowledge of the kind contained in this book. He would be wise to acquire it. J. F. T.

\section{Handbook of Chemistry}

A Reference Volume for all requiring Ready Access to Chemical and Physical Data used in Laboratory Work and Manufacturing. Compiled and edited by Dr. Norbert Adolph Lange, assisted by Gordon M. Forker. With an Appendix of Mathematical Tables and Formulas by Prof. Richard Stevens Burington. Second edition, revised and $\epsilon$ nlarged. Pp. xvi+ $1501+249$ (Appendix) +30 (Index). (Sandusky, Ohio : Handbook Publishers, Inc., 1937.) 6 dollars.

GIRST published in 1934 (see NATURE, 135, 978; 1935), this extremely useful handbook has now proceeded to a second and enlarged edition, containing nearly 1,800 pages of valuable and easily accessible information. Many of the tables have been revised while, in addition, there are sixteen new ones, the majority of which deal with the refractive indexes of solids and liquids. Another useful addition, and one which will prove of considerable aid in the identification of organic compounds, is the listing of the melting points of such compounds in order of ascending values. There has also been introduced a section on the numbering of ring systems.

Of the parts which have been revised or rewritten, mention may be made of the sections on first-aid, the nomenclature of organic compounds and, particularly, of that dealing with the use of organic reagents in inorganic analysis.

This handbook is handsomely bound and is excellently printed, the matter being clearly set forth without any appearance of overcrowding ; there is also a very complete index. Altogether the book will prove serviceable to every chemist and be the means of saving much time which would otherwise be spent in a tedious search of the literature.

G. R. D.

\section{Engineering}

Electrical Measurements

By Frank A. Laws. (Electrical Engineering Texts.) Second edition. Pp. xiv +739 . (New York and London: McGraw-Hill Book Co., Inc., 1938.) $36 s$.

COLLEAGUES of the late Prof. F. A. Laws have 1 seen the manuscript of the second edition of this text through the press, and have made sure that it contains the latest references and information which it is thought desirable to place before such undergraduate students as are looking forward to a career in electrical engineering. It is also intended to be of use to practising engineers who desire to understand the basis of testing technique which is found in practical work.

There is a great deal which the normal student does not need, and guidance from experienced teachers is therefore essential. There are also more extended references to the relevant literature than is usual ; although it would be the teacher's delight if students could be induced to read original literature, it must be confessed that they would not be able to discriminate between various types of work and extract basic principles, for that is all that they have time for, from modern work, which is complex and possesses refinements obscuring the main idea.

The newer high-voltage cable tests are included, but there is little that can appeal directly to the electrical engineering student who intends taking up high-frequency communication work. The involved shielding of modern high-impedance precision bridges might have been made clearer, with larger scale diagrams.

Radio-Frequency Electrical Measurements : a Guide for Radio Engineering Laboratory Instruction. By Prof. Hugh A. Brown. Second edition. Pp. xvi +384 . (New York and London: McGrawHill Book Co., Inc., 1938.) 24s.

7 HIS text is intended to be the basis of a fourthyear radio engineering course for telecommunication engineers, and assumes a normal knowledge of electrical engineering and physics. It consists of a large number of approaches to specified measurements; in the new edition exact procedures are outlined for the more difficult types of measurement. The cathode ray tube, with linear time-base, is freely used, and measurements of modulation and the frequency drifts of quartz-crystals, when used with valves as frequency controls, are included. The standardized methods of ordinary measurements on circuit elements are numerous, and students would require a plan in order to make a useful selection.

The course seems more balanced than others recently published, none of the experiments being trivial and none beyond a post-graduate student or a development engineer. The art and technique of radio is advancing rapidly, but its advancement depends mainly on precise measurement. The present text offers good training in this field.

L. E. C. H.

\section{Geography and Travel}

Gales, Ice and Men :

a Biography of the Steam Barkentine Bear. By Frank Wead. Pp. xiv $+240+13$ plates. (London : Methuen and Co., Ltd., 1938.) 12s. 6d. net.

"CALES, Ice and Men" is the history of what J may be the last of the ice ships, the Bear, which had a long and honourable career from 1874, when she was built, to 1935 , when she was laid up, perhaps finally. She was Newfoundland sealer, reseue ship (Greely, 1884), U.S. Revenue Service, with all that that entails in the far north Pacific, U.S. Coast Guard and finally, at the age of about sixty years, one of the ships of the Byrd Antarctic Expedition. The Bear was built at Dundee and almost certainly in the same yard as the Discovery, although Scott writes of "Stevens's" and Mi. Wead 